\title{
Problemas da analiticidade na semântica conceitual
}

DOI: http://dx.doi.org/10.21165/el.v49i3.2578

\section{Alex de Britto Rodrigues ${ }^{1}$}

\section{Resumo}

Este trabalho objetiva analisar o debate entre duas teorias semântico-conceituais: a Teoria da Semântica Conceitual, de Jackendoff (1983, 1987a, 1987b, 1990) e Pinker (1989, 2008), e a Teoria Representacional da Mente, de Fodor (1970, 1975, 1980, 1981, 1992, 1994, 1998, 2003). Segundo a primeira, o significado de um item lexical, tal como processado pela mente de modo subjacente à expressão linguística, poderia ser descrito em unidades abstratas menores, que seriam primitivos mínimos de significado acionados na mente, o que teria como base a analiticidade. Já para a segunda, um item lexical não poderia ter uma representação decomponível, ou seja, um item lexical teria uma representação atômica, em que seu significado abstrato processado na mente e subjacente à expressão linguística seria uma unidade simples, o que reforçaria a ideia da não plausibilidade da analiticidade. A perspectiva adotada para essa análise é a sugerida por Dascal (1998a, 1998b), conhecida como Teoria das Controvérsias, segundo a qual as trocas conversacionais polêmicas poderiam ser classificadas de três maneiras: discussão, disputa e controvérsia. A hipótese defendida neste trabalho é de que o debate em análise consiste em uma controvérsia por não se encaminhar para uma resolução consensual lógica, embora os argumentos levantados pelos interlocutores visem a um discernimento mínimo objetivo.

Palavras-chave: decomposicionismo semântico-conceitual; atomismo semânticoconceitual; analiticidade; Teoria das Controvérsias.

1 Centro Universitário de Andrade (UNIANDRADE), Curitiba, Paraná, Brasil; britto4r@gmail.com; https://orcid.org/0000-0002-7804-5482 


\title{
Analyticity problems in Conceptual Semantics
}

\begin{abstract}
This paper aims to analyze the debate between two semantic-conceptual theories: the Conceptual Semantics Theory developed by Jackendoff $(1983,1987 a, 1987 b, 1990)$ and Pinker $(1989,2008)$, and the Representational Theory of Mind, developed by Fodor (1970, $1975,1980,1981,1992,1994,1998,2003)$. According to the first one, the meaning of a lexical item, as it is processed by the mind and is underlying the linguistic expression, could be described by abstract smaller units, the meaning primitives in the mind, which is based on analyticity. In accordance with the second one, a lexical item could not have a decompositional representation, that is, a lexical item must be represented atomically, and its abstract and mental meaning underlying the linguistic expression must be a simple unit, which denies the possibility of analytic meaning. The perspective adopted in order to proceed with the analysis of this debate is the one suggested by Dascal (1998a, 1998b), known as Theory of Controversy, which states that the polemic conversational exchanges could be categorized in three types: discussion, dispute and controversy. This work defends that the debate under analysis is a controversy since it does not suggest a logical consensual resolution, although the interlocutor's arguments aim a minimum objective understanding.
\end{abstract}

Keywords: semantic-conceptual decompositionism; semantic-conceptual atomism; analyticity; Theory of Controversies.

\section{Introdução}

"Analiticidade" é um conceito desenvolvido na filosofia da linguagem e na semântica que diz respeito a uma propriedade do significado que não precisa ser verificada empiricamente no mundo (de modo externo à linguagem), pois o conhecimento do sistema linguístico já a determina. Por exemplo, definir "matar" como "causar a morte" é fazer uma relação analítica, já que não precisa de verificação externa à linguagem. Bastaria que um falante conhecesse as regras do sistema semântico-linguístico para atestar a verdade de um enunciado como "Maria morreu" caso o enunciado "João matou Maria" fosse verdadeiro, ou seja, se o segundo enunciado for dado como verdadeiro, o primeiro seria automaticamente verdadeiro, em uma relação de acarretamento que dispensa a verificação no mundo. Por outro lado, definir "matar" como "cometer um crime" já deixaria de ser uma relação analítica para ser uma relação sintética, pois dependeria da verificação das condições contextuais externas à linguagem, ou seja, se "ter matado" equivalesse a "cometer um crime", essa equivalência não seria definida a priori pelo sistema semânticolinguístico. 
A longa tradição de discussões a respeito da analiticidade não será o foco deste trabalho, mas apenas a problematização em torno desse conceito trazida para as relações analíticas das decomposições conceituais da Semântica Conceitual. O objetivo aqui, então, será analisar o debate entre duas linhas teóricas conflitantes dentro do campo da semântica preocupada com a construção de "conceitos" na mente: uma atomista, com seu principal expoente sendo Fodor (1970, 1975, 1980, 1981, 1992, 1994, 1998, 2003, 2008), e uma decomposicionista (Semântica Conceitual), com seus principais expoentes sendo Jackendoff (1983, 1987a, 1987b, 1990) e Pinker (1989, 2008). Não serão considerados detalhes exaustivos das duas perspectivas, porque não faz parte do objetivo avaliar qual é a "melhor" ou qual apresenta resultados mais satisfatórios, sendo ambas, então, apresentadas em uma dimensão geral relevante para que o lugar teórico de seus interlocutores seja compreendido. Desse modo, pode ocorrer uma contribuição no entendimento do debate em questão que elucide como as trocas conversacionais, e não apenas os "fatos" e as formulações lógicas, orientam a discussão em um determinado campo do conhecimento.

Após a apresentação das duas perspectivas, será abordada a proposta de análise segundo a qual o debate entre elas pode ser considerado uma controvérsia. A defesa dessa categorização terá como base a classificação das trocas conversacionais polêmicas proposta por Dascal (1998a, 1998b), que tem uma flexibilidade compatível com a dinâmica dos enunciados produzidos pelos interlocutores, ou seja, a proposta do autor não é rígida, pois as trocas conversacionais também não são, mas aponta para uma categorização relativamente segura baseada em análises empíricas de práticas discursivas.

\section{Quadro geral do debate: decomposicionistas versus atomistas}

O significado de um "item lexical", entendendo "item lexical" como uma unidade semânticolinguística básica (algo semelhante ao "morfema" no sentido da tradição estruturalista), pode ser tratado, entre outros modos, como: 1) algo decomponível, isto é, definível por meio de outros elementos não identificáveis em uma análise superficial; ou como 2) um átomo semântico, sendo a menor unidade discreta a participar da composição semântica das línguas. Claramente concorrentes, esses dois tipos de perspectivas, uma decomposicionista e outra atomista, sugerem um debate, nem sempre expresso claramente, no âmbito da cognição em que a representação mental de um item lexical ou se configura como uma estrutura formada por elementos "menores" ou corresponde à menor unidade semântica manipulada pelos mecanismos formais que compõem as sentenças.

O recorte considerado em nossa análise compreende, do lado decomposicionista, a perspectiva teórica conhecida como "Semântica Conceitual" (JACKENDOFF, 1983, 1987a, 1987b, 1990; PINKER, 1989, 2008; LEVIN, 1993; LEVIN; RAPPAPORT, 1995, 
1999, entre outros), e, do lado atomista, a perspectiva da Teoria Representacional da Mente (Representational Theory of Mind - RTM) (FODOR, 1970, 1975, 1980, 1981, 1992, 1994, 1998, 2003, 2008). Para a primeira perspectiva, um item lexical como "matar", por exemplo, seria representado, de modo simplificado, como [CAUSE BECOME DEAD], sendo os itens nessa representação primitivos que podem ser compreendidos como unidades abstratas discretas; já para a segunda perspectiva, a representação desse mesmo item seria, simplesmente, [KILL].

Nessa disputa sobre como os "conceitos" (unidades de significado manipuladas cognitivamente antes da geração de enunciados linguísticos) devem ser entendidos, as duas perspectivas se desenvolvem de modos assimétricos: os decomposicionistas têm uma "comunidade científica" (para usar um termo de KUHN, 2013), o que remete a certa estabilidade na elaboração de modelos de análise; já do lado atomista não há essa organização, pois seu principal proponente, Fodor, que desenvolve sua visão de outro lugar discursivo, isto é, da filosofia (como campo acadêmico), não estabelece um modelo de análise e de coleta de dados replicado por outros pesquisadores (apesar de Fodor ser respeitado no campo dos estudos cognitivos, sua perspectiva não resultou em um modelo de análise seguido por uma comunidade de pesquisadores).

Porém, mesmo os dois lados sendo de lugares discursivos diferentes, o debate passa a existir a partir do momento em que suas propostas entram em conflito em busca de um objetivo em comum. Ambas as perspectivas buscam explicar o que seriam os "conceitos" e qual é a participação deles na "linguagem do pensamento" (expressão utilizada por FODOR, 1975) ou no "mentalês" (como diria PINKER, 2008, mas esse termo também é usado por FODOR, 2008), um nível de representação subjacente à semântica das línguas naturais. Para as duas perspectivas, então, haveria uma linguagem mental que estabeleceria o conteúdo semântico, o que ocorreria de modo gerativo, pois haveria elementos e regras de formação finitas que possibilitariam infınitos arranjos conceituais (de significado mental).

Essa aproximação é crucial para entendermos uma das razões do debate. É porque há objetivos eassunções em comum dessetipo que surge o conflito, pois as duas perspectivas acabam por disputar um espaço de tentativa descritiva/explicativa específico. Mesmo com entendimentos tão diferentes sobre o que são os conceitos, como eles são formados e como formam unidades composicionais (isto é, unidades de significado formadas com base no agrupamento de outras unidade de significado), ao pressuporem que há "conceitos", processos de arranjos conceituais e estruturas subjacentes à semântica das línguas naturais, os autores dos dois lados observam a pertinência de considerarem uns aos outros, conforme Pinker (2008) deixa claro ao afirmar precisar levar em conta um livro chamado $A$ linguagem do pensamento (FODOR, 1975), já que teoriza justamente sobre a noção de "linguagem do pensamento". É em parte devido a essa dimensão de objetivos em comum que surge a tensão originada no debate. 
Entre as considerações em comum, merece destaque, como já delineado, que as duas perspectivas dão relevância ao componente gerativo. Mesmo que Fodor (1980) estivesse relativamente alinhado em certo momento com a perspectiva chomskyana, e os teóricos decomposicionistas da semântica conceitual sejam herdeiros de pressupostos da semântica gerativa, corrente teórica não endossada por Chomsky (RONAT, 1978), ou seja, mesmo com alinhamentos diferentes, as duas perspectivas se dizem gerativas para explicarem a produção de significados. Da mesma maneira, as regras de arranjos de conceitos, ditas finitas, assim como os elementos básicos manipulados por elas, são inatos. Desse modo, os dois lados do debate levam em conta, ainda que de maneiras diferentes, elementos de uma perspectiva gerativa e inatista de discussões a respeito da cognição que ganharam corpo após a "virada cognitiva" da década de 1950 (PUTNAM, 1987).

Outras semelhanças poderiam ser apontadas, mas essas já demonstram o quão os debatedores em questão concorrem em meio a postulações e objetivos aparentemente em comum. Portanto, resta-nos tratar da divergência entre elas, que é o que configurará o debate como uma controvérsia.

\section{Diferenças marcantes para o conflito teórico}

Um critério inicial para compreendermos uma das diferenças entre as duas perspectivas conflitantes é o caráter de falseabilidade. Popper (1980, p. 4) afirmara que "[...] toda teoria científica boa é uma proibição: ela proíbe certas coisas de acontecer. Quanto mais uma teoria proíbe, melhor ela é.". O autor, ao dizer isso, referia-se ao problema de algumas teorias não se mostrarem possíveis de serem refutadas e de elas darem conta de uma excessiva quantidade de explicações. Em outros termos, uma teoria que não pode ser falseada em nenhuma condição, isto é, sobrevive como verdadeira em qualquer situação, não pode, portanto, ser verificada. Longe de reforçar um posicionamento normativista segundo o qual as teorias "têm de ser assim", mas assumindo que a falseabilidade tem um papel distintivo importante na ciência (mesmo em um plano ideal que norteia uma visão de ciência), essa ideia nos é útil para demonstrar algumas características relevantes das perspectivas em questão.

O atomismo léxico-conceitual de Fodor parece não ter problemas de se adequar a esse critério. Se um determinado conceito simples corresponde a um determinado item lexical, o que faz de um item lexical um átomo conceitual, então bastaria encontrarmos uma unidade conceitual menor para que a tese de Fodor fosse refutada. O próprio autor (FODOR, 1975) apresenta algumas condições que poderiam falsear sua proposta, condições essas que diriam respeito à identificação de uma estrutura conceitual interna a um item lexical por meio da análise do escopo de um advérbio (se esse escopo poderia alcançar apenas uma suposta parte, um primitivo abstrato, desse conceito) ou da retomada pronominal de apenas um desses primitivos abstratos. 
Outra condição que poderia falsear sua tese atomista seria a diferença de processamento entre um item lexical mais complexo (com mais primitivos em sua estrutura interna) do que outro (como um item simples, com apenas um primitivo em sua estrutura). $O$ autor (FODOR, 1980) acaba por demonstrar que essa diferença não é verificada, ou seja, não haveria diferença no tempo de processamento entre um item como "kill", supostamente mais complexo em relação a uma suposta estrutura conceitual, e um item como "die", que seria menos complexo. Desse modo, mesmo tendo por foco se posicionar contra o decomposicionismo léxico-conceitual nessas considerações, Fodor deixa claro que sua proposta poderia ser falseada em várias situações (mas, conforme a sua defesa, isso não chegou a ocorrer).

A argumentação de Fodor, em relação a essas considerações, poderia ser descrita resumidamente da seguinte maneira:

- Condições de falseamento do atomismo conceitual: evidências de que há estruturas conceituais. ${ }^{2}$

- $\quad$ Se atomismo $\rightarrow \sim$ decomposicionismo

- Se decomposicionismo $\rightarrow \sim$ atomismo

- Há condições em que o atomismo seria falseado.

- Condições de falseamento não verificadas $\rightarrow$ Evidência para o atomismo e não plausibilidade do decomposicionismo.

Essa descrição emerge do discurso de Fodor (1970, 1975, 1980, 1981, 1992, 1994, 1998, 2003), não sendo explicitada dessa forma (apesar de ficar relativamente clara em seus textos). Não se baseia inteiramente em relações lógicas, mas se sustenta empiricamente por meio de evidências aparentemente plausíveis. Na primeira parte, como já dito, o autor demonstra condições de falseamento de sua teoria. A segunda e a terceira parte dessa descrição aparecem em vários de seus textos (de maneira explícita, aparece no texto de 1998) e evidencia a incompatibilidade das duas perspectivas, o que implicaria, caso uma fosse verdadeira (ou próxima disso), que a outra fosse falsa (ao desqualificar a proposta concorrente, o autor, portanto, está respaldando a sua). A penúltima parte, seguindo a proposta de Popper, seria evidenciada pelas condições de falseabilidade comentadas anteriormente. Por fim, segundo Fodor, nenhuma dessas condições é verificada, o que coloca automaticamente em xeque a proposta decomposicionista (com base nas duas primeiras partes), fazendo com que o atomismo surja como alternativa mais sólida.

2 Isso não provaria a "verdade" da proposta decomposicionista, já que, seguindo a perspectiva popperiana, uma teoria não pode ser dita como "verdadeira"; apenas pode ser dita, se houver condições para isso, como "falsa". 
Lembremos que Fodor, ao seguir essa linha de raciocínio e ao se referir a seus opositores, sugere paralelamente algumas condições para que uma proposta decomposicionista seja aceita, e ser falseável seria uma delas (apesar de o autor não deixar isso explícito, nas condições que ele sugere e no decorrer de seus textos isso pode ser compreendido como relevante). Disso pode ser inferida uma subcrítica implícita: se a proposta decomposicionista não está de acordo com essas observações, ela já é problemática de saída. Vejamos como isso pode ser verificado no discurso de decomposicionistas.

As duas últimas partes do resumo apresentado sobre a argumentação de Fodor, que tratam da falseabilidade, requerem uma análise com mais atenção por serem mais contestáveis (não há polêmica, em relação aos debatedores, a respeito das três primeiras partes). Para tanto, lembremos o que Jackendoff (1988) e Pinker (2008) afirmam.

Para rebater uma crítica de Fodor, de que uma representação do termo "matar" não poderia corresponder a [CAUSE BECOME DEAD], pois um falante leva o mesmo tempo para processar (compreender) o termo "matar" que leva para compreender o termo "morrer" (que teria uma representação mais simples na perspectiva decomposicionista, como [BECOME DEAD]), os autores se utilizam do conceito de chunk. Um chunk seria uma espécie de agrupamento de primitivos, que formariam uma estrutura conceitual complexa processada como uma unidade, tal como ocorreria com uma estrutura conceitual simples, formada por apenas um primitivo. Isso explicaria a falta de diferença no processamento (em relação a tempo e a dificuldade de compreensão por parte do falante) entre "matar" e "morrer" ("matar" corresponderia a um chunk dos primitivos CAUSE, BECOME e DIE, o que o faria ser processado da mesma maneira que "morrer", também um chunk, apesar de ser formado apenas por BECOME e DIE).

É importante localizar esse argumento porque, de modo geral, ele aparece disperso e difuso nos trabalhos decomposicionistas conceituais sob a seguinte forma aproximada: um primitivo conceitual não tem o mesmo funcionamento que um item lexical, pois são elementos presentes em níveis diferentes de abstração. Isso não costuma ser problematizado nos trabalhos de decomposicionistas conceituais (LEVIN, 1993; CANÇADO et al., 2013, entre outros), o que parece estar relacionado a certa "obviedade" que não precisaria de uma discussão extensa. Seria óbvio (e isso Pinker (2008) parece sugerir ao dizer que a proposta de Fodor está relacionada à falta de bom senso), então, que uma estrutura conceitual abstrata não tem de ser processada como uma estrutura superficial (já que uma composição entre dois ou mais itens lexicais superficiais, obviamente, requer mais tempo de processamento mental), e o conceito de chunk daria conta disso.

Porém, o poder explicativo dos chunks é relativamente grande, o que, em uma perspectiva popperiana, não é uma qualidade teórica. Eles podem dar conta de qualquer caso de falta de verificação empírica das estruturas conceituais: como o que temos concretamente são itens lexicais ("palavras") e estruturas formadas composicionalmente por eles 
("sentenças"), só seria possível verificar algo por meio de análises que considerassem itens lexicais isolados e/ou presentes em sentenças, mas qualquer problema para a proposta decomposicionista apontado com base na falha de relação entre estrutura conceitual abstrata e realização superficial na sentença seria rebatido com a postulação de que as estruturas conceituais abstratas funcionam sem se espelharem na estrutura superficial, sendo que uma estrutura lexical concreta e composicionalmente formada opera não com primitivos isolados, mas com chunks, cuja dimensão estrutural é abstrata e não seria identificável facilmente. Em outros termos, em razão de a proposta de chunks poder responder qualquer problema imaginado a respeito de qualquer incompatibilidade sugerida entre uma estrutura superficial e uma estrutura conceitual de primitivos, ela não pode ser falseada.

Como já havíamos adiantado, não se trata de seguir uma perspectiva normativista e excluir uma perspectiva teórica do rótulo de "ciência" por não contemplar condições de falseabilidade. Nosso intuito, com esse apontamento, é demonstrar que, por algum motivo, uma perspectiva teórica, mesmo com problemas em termos popperianos, não tem problemas de sobrevivência e desenvolvimento. É preciso, então, ir além da perspectiva de Popper para explicar esse quadro. Não iremos, portanto, apenas analisar as teorias em si, mas como os autores as constroem por meio de suas argumentações.

\section{Trocas polêmicas e controvérsias}

Uma das razões de as posições descritivistas e normativistas dominantes na filosofia da ciência na segunda metade do século XX (posições essas influenciadas, em certa medida, por Popper e Kuhn) estarem presas em uma espécie de impasse, algo que as tornaria insuficientes para tratarem de aspectos relevantes do fazer científico, segundo Dascal (1998b, p. 147), é o fato de elas terem negligenciado o papel das controvérsias. Em uma noção introdutória, que será estendida na sequência, "controvérsias" são trocas conversacionais polêmicas que marcam, de uma determinada maneira, uma divergência em um debate, o que é crucial, segundo o autor, para a ciência. Sendo "trocas conversacionais", elas requerem uma perspectiva pragmática para serem analisadas, o que é atendido pela proposta de Dascal (1998a, 1998b, 2005) por meio da aplicação de noções pragmáticas desenvolvidas para uma análise da conversação.

O uso de uma perspectiva pragmática para analisar as trocas polêmicas, que dão corpo aos debates, é justificada pela insuficiência de uma abordagem estritamente semântica/lógica³. Como diz Dascal (2005, p. 302), explicações semânticas a respeito das trocas polêmicas (mais especificamente, das controvérsias) geralmente se limitam a caracterizações em termos de presença ou ausência de relações lógicas entre as

3 Em certo sentido, parte da perspectiva de Popper também poderia ser considerada insuficiente pelo mesmo motivo, já que o critério da falseabilidade é formulado logicamente. 
afirmações feitas pelos debatedores. Esse tipo de análise, criticado por Dascal por ser abstrato demais, é exemplificada pela proposta de Nowakowska (1985, p. 138 apud DASCAL, 2005, p. 302), segundo a qual as trocas conversacionais polêmicas, pelo menos as ditas "controvérsias", resumem-se a um conjunto de afirmações verificáveis de modo preciso não compatível com outro conjunto de afirmações também verificáveis de modo preciso de tal modo que surge uma inconsistência entre os dois conjuntos a ser "resolvida" por uma mudança pontual de posicionamento. Essa proposta estritamente semântica, segundo Dascal, deixa de considerar que uma controvérsia real nunca se resume a uma única diferença de opinião verificada sobre uma determinada questão, já que a discordância ocorre em relação a uma série de tópicos, aparentemente em torno de uma divergência central.

Não seria a mudança de uma ou outra opinião que resolveria uma controvérsia, pois vários fatores estão envolvidos na defesa dos posicionamentos, que podem causar uma polarização em que os lados perpetuam o debate à revelia de possíveis argumentos logicamente construídos. Além disso, para resolver um debate em termos estritamente semânticos, seria preciso:

(a) solucionar todos os problemas de interpretação que podem surgir em relação aos significados pretendidos dos textos e das elocuções empregados na controvérsia e (b) deixar de lado os elementos da controvérsia que podem ser considerados como meramente "retóricos" ou então "externos" em relação ao núcleo. Uma vez libertadas de todos os problemas de interpretação e de todos os elementos retóricos, as controvérsias podem ser muito mais receptivas a uma análise lógica. Mas quem as libertará e de acordo com quais critérios? Presumese que seja um observador "neutro" - um "juiz imparcial de controvérsias" [...] dotado com poderes interpretativos objetivos e confiáveis. (DASCAL, 2005, p. 302-303).

Acreditar que essa imparcialidade objetiva, com uma precisão interpretativa dos lados em debate, não é possível não significa descartar qualquer análise semântica/lógica. Lembremos que Dascal considera insuficiente uma abordagem estritamente semântica, com o que concordamos, o que não significa que a considere irrelevante ou inútil. $O$ autor faz a ressalva de que, por mais que sejam difíceis de formalizar, alguns parâmetros - como centralidade, grau de polarização, distância, entre outros - podem ser eventualmente considerados na compreensão formal do quadro em que as trocas conversacionais polêmicas ocorrem, o que pode estabelecer algumas distinções lógicas e aumentar a adequação descritiva. No entanto, a ocorrência das controvérsias dificilmente se limita ao nível da linguagem-objeto, pois elas acionam questões mais amplas, difíceis de serem formalizadas. Como exemplo dessas questões há o fato de os debatedores não costumarem aceitar interpretações e avaliações, mesmo formuladas logicamente, de seus oponentes teóricos. Esse tipo de rejeição não é periférico nas controvérsias; pelo contrário, é um traço fundamental para caracterizá-las. 
$\mathrm{Na}$ sequência, trataremos da caracterização das trocas polêmicas, entre elas as controvérsias. Como veremos, o debate analisado por nós se mostrará como uma controvérsia, mas não de modo totalmente preciso, pois algumas de suas características representarão uma dificuldade para a delimitação no quadro tipológico das trocas polêmicas sugerido por Dascal.

\section{Tipos de trocas polêmicas}

As trocas polêmicas (ou "debates") desempenham, conforme Dascal (1998a), um papel de dimensão epistemológica muito importante. O autor observa que, para muitos pensadores de diferentes vertentes, incluindo desde pensadores clássicos a pensadores do século XX (como Popper e Kuhn), o conhecimento é alcançado por meio do exercício da razão crítica, o que acaba sendo quase um consenso. Esse exercício no meio científico e acadêmico é, basicamente, uma atividade dialógica cuja manifestação mais natural são as trocas polêmicas. Por esse motivo, compreender tais trocas é importante para apreender o significado de uma teoria e as mudanças conceituais nos diversos domínios de conhecimento. Essas trocas, no entanto, não costumam ser consideradas por filósofos e historiadores da ciência como práticas dialógicas baseadas na atividade crítica. Por esse motivo, Dascal aponta que cabe às ciências do uso da linguagem (como a pragmática, a análise da conversação e a retórica) analisar as trocas polêmicas nessa dimensão (conversacional) e ajudar os epistemologistas com evidências empíricas que emergem delas, o que geralmente falta a seus modelos abstratos.

As trocas conversacionais polêmicas podem ser estudadas em diferentes níveis, sendo um deles, conforme sugere Dascal (1998a), o nível estratégico. Esse nível compreende determinados padrões conversacionais, o que resulta em três tipos de trocas polêmicas: a discussão, a disputa e a controvérsia. Nenhuma troca polêmica concreta é pura, isto é, nenhuma tem características apenas de um tipo, o que faz dessa tipologia um instrumento de análise flexível, mas suficientemente adequado para a identificação e caracterização centrais. Portanto, essa sugestão tipológica deve ser confrontada com casos concretos, sem esperarmos um enquadramento perfeito. Porém, antes de explicitar as características de cada um dos tipos de trocas polêmicas, convém apontar alguns elementos importantes para todos os três, o que deve ser verificado antes da identificação com um deles.

Uma troca polêmica envolve pelo menos dois participantes que se dirigem mutuamente em um confronto de atitudes, opiniões, argumentos e/ou teorias. Por essa razão, as confrontações em que um dos lados não se dirige claramente para seu opositor não são consideradas trocas polêmicas ${ }^{4}$. No caso do debate entre atomistas e decomposicionistas

4 A expressão "troca polêmica" parece mais adequada nesse sentido, pois "debate", com um caráter menos técnico, pode ser usado para confrontações em que um dos lados não se dirige claramente ao outro. Porém, as duas expressões são intercambiáveis neste trabalho. 
conceituais, Fodor $(1981,1998,2003,2008)$ se dirige claramente a autores como Pinker e Jackendoff (apesar de, por vezes, se referir a um opositor teórico genérico), e esses dois autores (JACKENDOFF, 1983, 1990, 1995; PINKER, 2008) expressam claramente oposição a Fodor. Porém, vale relembrar que as confrontações não são simétricas: Fodor se dirige muito mais a seus opositores do que o inverso, o que sugere haver uma maior desconsideração dos trabalhos do autor por parte dos decomposicionistas conceituais. Além disso, Fodor é apenas um autor na defesa do atomismo conceitual que se opõe expressamente aos decomposicionistas, ao passo que os decomposicionistas podem ser relacionados a uma comunidade, conforme já comentado. Por fim, mesmo que apenas dois autores decomposicionistas (Jackendoff e Pinker, que estão entre os mais referenciais) do nosso recorte se dirijam a seu oposicionista teórico (o que já garante a condição de "troca polêmica"), todos os demais que seguem os mesmos pressupostos e procedimentos de análise (principalmente LEVIN, 1993; LEVIN; RAPPAPORT HOVAV, 1995) formam, com os dois autores mencionados, um corpo relativamente coeso, e acabam por participar do debate de forma indireta - como se baseiam em Jackendoff $(1990,1995)$ e/ou Pinker (1989; 2008) sem fazer ressalvas em relação aos apontamentos contra a perspectiva de Fodor, engrossam o grupo criticado pelo atomista.

Identificados os opositores teóricos, podemos verificar a qual tipo a troca polêmica analisada por nós melhor se relaciona. Tendo esse objetivo em mente, iremos expor a tipologia sugerida por Dascal, identificando quais características do debate entre decomposicionistas e atomistas podem ser relacionadas a elas. Comecemos pela caracterização do primeiro tipo, a "discussão".

Uma troca polêmica do tipo "discussão" tem como objeto de divergência um tópico claramente definido e delimitado. Os debatedores tendem a identificar o problema que causa a discordância, que pode ser resolvido, por exemplo, por uma contraprova, um experimento, a correção de uma análise, entre outros meios disponíveis para verificação e teste de um posicionamento teórico. Esse tipo de troca polêmica, portanto, permite e se encaminha para o estabelecimento da "verdade", entendida como tal de modo consensual entre os debatedores. Não é preciso se estender mais na explicação desse tipo para verificarmos a sua não correspondência com o debate entre atomistas e decomposicionistas conceituais. Como já notado, esse debate não se encaminha para qualquer tipo de consenso referente a experimentos e a procedimentos de análise. Pelo contrário: como veremos na descrição dos outros dois tipos (que serão, portanto, mais reveladores), esse debate, da forma como se configura, não se encaminha para uma solução.

Uma disputa também parece ter como objeto de divergência um tópico bem definido e delimitado. Porém, não há procedimentos de verificação consensualmente aceitos, o que não permite uma solução. No limite, uma disputa pode ser apenas dissolvida, o que depende das atitudes dos debatedores. Além disso, diferentemente de uma 
discussão, em que um conflito tende a ser percebido como algo lógico, em disputas um conflito tende a ser visto de modo mais ideológico (que é, conforme Dascal, 1998a, algo atitudinal e valorativo). Por fim, um debatedor em meio a uma disputa tende a buscar ser reconhecido como o vencedor, não importando se sua posição é verdadeira ou não. Como diz Dascal (1998a, p. 8), o debatedor engajado em uma disputa "começa e termina a disputa (qualquer que seja a saída "externa" [menos lógica, mais ideológica]) convencido de que ele está certo"5.

É possível relacionar, pelo menos parcialmente, o debate analisado por nós com esse segundo tipo. A divergência parece estar bem delimitada: ou o conceito lexical tem uma estrutura formada por "conceitos menores" primitivos, ou ele é atômico. Além disso, os procedimentos de verificação não são consensualmente aceitos por ambas as partes: as análises e os experimentos de Fodor não são aceitos por Jackendoff $(1983,1990,1995)$ e por Pinker (2008) por supostamente não considerarem de modo adequado a diferença entre uma estrutura superficial (de itens lexicais) e uma estrutura abstrata conceitual (de primitivos); por outro lado, Fodor (1998) previa que uma proposta decomposicionista, para ser plausível, deveria ter seus primitivos referenciados claramente, o que implicaria relações verificáveis e recuperáveis superficialmente (de outro modo, a proposta não seria verificável - nem falseável), com o que os decomposicionistas defensores da semântica conceitual não concordam.

Outra característica das disputas que parece ser atendida é o fato de os debatedores (mais do lado dos decomposicionistas) terem "convicção" de estarem certos sem necessariamente terem demonstrado logicamente isso, o que pode ser exemplificado pela acusação de Pinker (2008) de que falta bom senso para a proposta de Fodor, ou pela opção de Jackendoff (1983) de não problematizar a plausibilidade da analiticidade por considerar que o debate filosófico em torno dela se tornou infrutífero, ao mesmo tempo que considera a analiticidade como dada por garantido ao defini-la como "verdade em virtude da estrutura conceitual". Jackendoff, ao fazer isso, ignora que seu debatedor, Fodor, parte desse mesmo debate ao se dizer "quineano"6 e que, por isso, contrapor-se a ele poderia demandar contemplar essa discussão. A convicção de que estão certos em relação a pressupostos básicos parece um traço constante no debate entre atomistas e decomposicionistas, mas mais pelo lado decomposicionista.

Porém, esse debate contém alguns elementos que colocam em dúvida se a divergência que ele revela é, de fato, claramente definida e delimitada, pois os dois lados discordam do que seria uma proposta decomposicionista plausível (apesar de um dos lados achar que, mesmo podendo ser plausível, ela é falsa). Além disso, como é um debate que se estende

5 No original: "begins and ends the dispute (whatever its "external" outcome) convinced he is right." 6 Quine é um dos principais críticos da diferenciação entre significado analítico e significado sintético. Para o autor, nenhum significado é puramente analítico. 
desde o desenvolvimento da semântica conceitual na década de 1980, sob influência da semântica gerativa das décadas de 1960 e 1970, não parece haver claramente uma tendência à dissolução. Cabe, então, analisarmos o terceiro tipo de troca polêmica, a controvérsia, para verificarmos se outros elementos caracterizadores pertinentes para nossos propósitos são elucidados.

A controvérsia é um tipo de troca polêmica intermediária entre a discussão e a disputa. Não consiste em apenas um problema claramente delimitado, apesar de poder começar assim, mas em uma diversidade de problemas que revelam divergências mais profundas (DASCAL, 1998a). Esse tipo não se encaminha para uma solução lógica nem para uma dissolução, mas para uma possível resolução com base em defesas sustentadas cumulativamente, em que os debatedores apresentam argumentos que acreditam fortalecer seus posicionamentos. Essa possível resolução se dá em uma espécie de "balança", em que o maior número de argumentos ou os argumentos mais fortes favorecem mais um lado do que o outro. Caso um lado seja mais argumentativamente favorecido (não necessariamente no sentido lógico ${ }^{7}$ ), isso não significa que o debate é necessariamente encerrado, pois o outro lado busca equilibrar e ultrapassar o peso argumentativo de seu opositor teórico. A resolução (muitas vezes provisória) se daria quando um dos lados se visse vencido com o acúmulo de argumentos do outro, o que poderia esclarecer a diferença entre as duas posições, revelando que uma é mais plausível que a outra.

Voltando ao debate que é nosso objeto de análise, podemos notar que a divergência que dele emerge parece estar, como já dito, claramente delimitada e definida: um lado defende um decomposicionismo léxico-conceitual e o outro diz que isso não é viável. Porém, no decorrer do debate, vemos que, para o lado decomposicionista, não há problema em a estrutura conceitual recuperável da decomposição não ter correspondência clara com a estrutura superficial ou não ter uma relação com ela pré-determinada que restringe as estruturas conceituais, ao contrário do que sugere Fodor para uma possível decomposição ser plausível. As relações verificadas nas estruturas superficiais das sentenças, que corroboram as estruturas conceituais decomposicionistas, são geralmente as alternâncias, como a causativa, sustentadas por análises intuitivas aparentemente plausíveis'; porém, qualquer outra relação sintática ou semântica (ou qualquer observação sobre o processamento da sentença que coloquem em xeque as estruturas conceituais são "explicadas" pela ocorrência de chunks. Em outros termos, no quadro decomposicionista, se uma determinada relação sintática (como as alternâncias)

7 Por "argumento", Dascal entende os enunciados que ajudam a convencer sobre uma determinada posição, independentemente de serem lógicos ou conclusivos. Veremos mais sobre isso na próxima subseção.

8 Uma alternância causativa é como a promovida no seguinte par de sentenças: 1) João quebrou o copo; 2) O copo quebrou. Nesse par de sentenças, o verbo "quebrar" se mostra em uma alternância, em que pode funcionar com um sujeito que "causa" o evento ou sem um sujeito causador. 
ou semântica (correspondentes geralmente a intuições, que podem ter caráter inferencial não lógico, mas podendo também compreender a dimensão semântica dos papéis temáticos ou qualquer outra noção semântica) corroboram como indícios da existência de decomposições em estrutura conceitual de primitivos, elas são consideradas; se não corroboram, são descartadas, não sendo consideradas como contra-argumentos plausíveis em razão dos chunks.

Ainda sobre as divergências que surgem do debate, uma das mais salientes é sobre a aquisição da linguagem. Para o lado atomista, todos os conceitos lexicais são inatos, e no decorrer do amadurecimento, em que a criança tem experiências com o mundo, esses conceitos emergem, dando a ilusão de um aprendizado. Para o lado decomposicionista, apenas os primitivos conceituais são inatos, sendo os conceitos lexicais formados criativamente (no sentido gerativo) por eles. Por mais que Fodor se estenda na explicação de sua proposta, ela parece, à primeira vista, contraintuitiva, e essa aparência ajuda a respaldar, no âmbito da controvérsia, a proposta decomposicionista.

Vemos, assim, que a divergência vai além da mera oposição entre decomposição léxico-conceitual e átomo léxico-conceitual, pois compreende também quais relações sintáticas e semânticas são ou não relevantes, como se dá a aquisição e, recordando as discussões anteriores, se é relevante ou não considerar a problematização a respeito da analiticidade. Além disso, notamos que o argumento dos chunks, mesmo que tenha problemas em termos popperianos, faz a balança, relacionada à controvérsia, tender para o lado decomposicionista. Essa metáfora da balança argumentativa sugerida por Dascal nos é útil para entender a força que a proposta decomposicionista conceitual tem. Como já dito, essa proposta permite uma quantidade relativamente grande (em relação à proposta atomista) de análises e descrições dos itens lexicais que dá a impressão de uma sustentação empírica consistente. Um corpus de análise grande, a falta de algo desse tipo para a proposta atomista e a ideia atomista de conceitos como [CARBURADOR] serem inatos parecer contraintuitiva também fazem a balança tender para o lado decomposicionista de tal modo que Pinker, recordemos, diz que Fodor despreza o bom senso. Em outros termos, não seria bom senso sustentar argumentos que têm tão pouca força em um debate - e essa ideia de sustentação é característica das controvérsias. Por essa razão, o debate analisado por nós é uma controvérsia com algumas características de disputa, o que é possível, segundo Dascal (1998a), pois os tipos de trocas polêmicas raramente são puros, isto é, raramente têm características de apenas um.

\section{Considerações finais}

Tendo posto que o debate em análise trata de uma controvérsia, em que os debatedores buscam desequilibrar a disputa argumentativa em favor de sua própria perspectiva, ele não se encaminha para uma solução nem uma dissolução. Desse modo, os impasses (relacionados a questões em aberto ou pouco esclarecidas, ou à falta de compreensão 
entre os debatedores) que surgem, se não podem ser solucionados, também não tendem a encerrar o debate. Por isso, analisá-los sob um ponto de vista externo ao debate pode indicar outros caminhos de análise, não para encerrar a controvérsia, já que sua natureza é progredir com o uso de argumentos pelos debatedores, nem para mostrar qual caminho é o correto, já que nossa proposta não é normativa, mas para possibilitar uma tentativa de elucidação e explicação. Essas considerações consistem em identificar os impasses centrais e analisá-los a fim de observar o que não é levado em conta pelos debatedores.

Esses impasses, ou questões em aberto, são típicos das controvérsias, pois esse tipo de troca polêmica não se encaminha para uma solução. Com impasses sem solução e com a perspectiva de perpetuação da controvérsia, restaria apontar, em vez de soluções, caminhos alternativos de considerações, que investissem a atenção na problematização desses impasses, o que poderia contribuir para uma elucidação do debate, para a reformulação de argumentos e esclarecimentos de ambos os lados ou para a formulação de uma terceira linha de pesquisa que partisse dessa problematização. Não se trataria de fechar as questões em aberto, mas de olhar externamente para o debate e tentar desvelálas a fim de que estejam disponíveis mais claramente para análise.

\section{REFERÊNCIAS}

BACHELARD, G. Novo espírito científico. São Paulo: Abril Cultural, 1978 [1934].

CANÇADO, M. et al. Catálogo de verbos do português brasileiro: classificação verbal segundo a decomposição de predicados. Belo Horizonte: Editora UFMG, 2013. v. 1: Verbos de mudança.

CARNAP, R. Meaning and Necessity. Chicago: University of Chicago Press, 1947.

DASCAL, M. Interpretação e compreensão. São Leopoldo: Editora Unisinos, 2005.

DASCAL, M. Types of polemics and types of polemical moves. In: CMEJRRIKOVA, S.; HOFFMANNOVA, J.; MULLEROVA, O.; SVETLA, J. (ed.). Dialogue Analysis VI. Tübingen: Max Niemeyer, 1998a. Disponível em: http://www.tau.ac.il/humanities/philos/dascal/ papers/pregue.htm. Acesso em: 09 set. 2016.

DASCAL, M. The study of controversies and the theory and history of science. Science in Context, n. 11, v. 2. p. 147-154, 1998b.

FODOR, J. The Language of Thought Revisited. Oxford: Clarendon Press, 2008. 
FODOR, J. Hume variations. Oxford: Clarendon press, 2003.

FODOR, J. Concepts: where cognitive science went wrong. Oxford: Clarendon press, 1998.

FODOR, J. The Elm and the Expert: Mentalese and its Semantics. Cambridge: MIT Press, 1994.

FODOR, J. A Theory of Content and Other Essays. Cambridge: MIT Press, 1992.

FODOR, J. Representations: Philosophical Essays on the Foundations of Cognitive Science. Brighton: The Harvester Press, 1981.

FODOR, J. On the Impossibility of Acquiring "More Powerful" structures. In: PIATTELLIPALMARINI, M. (ed.). Language and Learning: The Debate Between Jean Piaget and Noam Chomsky. Havard: Havard University Press, 1980.

FODOR, J. The Language of Thought. New York: Thomas Y. Crowell Company, 1975.

FODOR, J. Three reasons for not deriving "kill" from "cause to die". Linguistic Inquiry, Cambridge, n. 4, v. 1, p. 429-438, out. 1970.

FODOR, J.; GARRETTE, M. F.; WALKER, C. T.; PARKES, C. H. Against definitions. Cognition, n. 8, p. 263-367, 1980.

FODOR, J.; LEPORE, E. Holism: a shopper's guide. Oxford: Blackwell, 1993.

GOLDBERG, A. E.; JACKENDOFF, R. The English resultative as a family of constructions. Language, v. 80, n. 3, p. 532-568, 2004.

GOLDBERG, A. E. Constructions: a construction grammar approach to argument structure. Chicago: University of Chicago Press, 1995.

JACKENDOFF, R. S. Foundations of language: brain, meaning, grammar, evolution. New York: Oxford University Press, 2002.

JACKENDOFF, R. S. Languages of the Mind: Essays on Mental Representation. Cambridge: MIT Press, 1995.

JACKENDOFF, R. S. Semantic structures. Cambridge: MIT press, 1990. 
JACKENDOFF, R. S. Towards an Explanatory Semantic Representation. Linguistic Inquiry, v. 18, n. 3, p. 369-411, 1987a.

JACKENDOFF, R. S. The Status of Thematic Relations in Linguistic Theory. Linguistic Inquiry, n. 3, v. 18, p. 369-411, 1987b.

JACKENDOFF, R. S. Semantics and cognition. Cambridge: MIT press, 1983.

KATZ, J. J. The philosophy of language. New York: Harper and Row, 1966.

KATZ, J. J.; FODOR, J. The structure of a Semantic Theory. Language, v. 39, n. 2, p. 170210, 1963.

KUHN, T. S. A estrutura das revoluções científicas. Tradução Beatriz Vianna Boeira e Nelson Boeira. 12. ed. São Paulo: Perspectiva, 2013.

LAKOFF, G. Toward generative semantics. In: McCAWLEY, J. D. Notes from the linguistic underground. New York: Academic Press, 1976 [1963].

LEVIN, B. English Verb Classes and Alternations: A Preliminary Investigation. Chicago: University of Chicago Press, 1993.

LEVIN, B.; RAPPAPORT HOVAV, M. Argument realization. Cambridge: Cambridge University Press, 2005.

LEVIN, B.; RAPPAPORT HOVAV, M. Two Structures for Compositionality Derived Events. In: MATTHEUS, T.; STROLOVITCH, D. (ed.). Proceedings of SALT 9. Ithaca: Cornell Linguistics Circle Publications, 1999.

LEVIN, B.; RAPPAPORT HOVAV, M. Unaccusativity: At the Syntax Lexical Semantics Interface. Cambridge: MIT Press, 1995.

LIEBERMAN, P. The biology and evolution of language. Cambridge: Harvard University Press, 1994.

PERELMAN, C. L'Empire Rhétorique: Rhétorique et Argumentation. Paris: Vrin, 1977. 
PIATTELI-PALMARINI, M. The rise of selective theories: a case study and some lessons from immunology. In: DEMOPOULOS, W.; MARRAS, A. (org.). Language learning and concept acquisition. Norwood: Ablex, 1986.

PIATTELI-PALMARINI, M.; CECHETTO, C. In: MANDELL, C.; McCABE, A. (org.). The problem of meaning: behavioral and cognitive perspectives. New York: Elsevier, 1997.

PINKER, S. Do que é feito o pensamento. Tradução Fernanda Ravagnani. Rio de Janeiro: Companhia das Letras, 2008.

PINKER, S. Learnability and Cognition: The Acquisition of Argument Structure. Cambridge, MA: MIT Press, 1989.

PITT, D. Mental Representation. In: ZALTA, E. N. (ed.) The Stanford Encyclopedia of Philosophy. 11 dez. 2012. Disponível em: https://plato.stanford.edu/archives/fall2013/ entries/mental-representation/. Acesso em: 03 maio 2015.

POPPER, K. R. Conjecturas e Refutações. Brasília: Editora da UnB, 1980.

PUTNAM, L. R. Language, Language Development and Reading: Noam Chomsky interviewed by Lillian R. Putnam. Reading Instruction Journal, inverno de 1987. Disponível em: https://chomsky.info/1987 /. Acesso em: 30 jul. 2016.

QUINE, W. V. Dois dogmas do empirismo. In: QUINE, W. V. De um ponto de vista lógico. Tradução Antonio lanni Segatto. São Paulo: UNESP, 2010 [1980].

QUINE, W. V. Word and Object. Cambridge, MA: MIT Press, 1960.

RAPPAPORT HOVAV, M.; DORON, E.; SICHEL, I. (org.). Lexical semantics, syntax and event structure. Nova York: Oxford University Press, 2010.

REY, G. The Analytic/Synthetic Distinction. In: ZALTA, E. N. (ed.) The Stanford Encyclopedia of Philosophy. 21 dez. 2015. Disponível em: http://plato.stanford.edu/archives/win2015/ entries/analytic-synthetic/. Acesso em: 25 dez. 2015.

RONAT, M. Conversaciones con Chomsky. Tradução Beatriz Dorriots. Barcelona: Granica Editor, 1978. 